\title{
TREATMENT FOR WEIGHT LOSS OF GRADE III OBESE PATIENTS IN THE HOSPITAL ENVIRONMENT: COMPARATIVE STUDY BETWEEN HOSPITALIZATION AND AMBULATORY PROGRAMS
}

\section{TRATAMIENTO PARA LA PÉRDIDA DE PESO EN PACIENTES CON OBESIDAD GRADO III EN AMBIENTE HOSPITALARIO: ESTUDIO COMPARATIVO ENTRE PROGRAMAS DE INTERNACIÓN Y AMBULATORIO}

\author{
Paula Garcia Chiarello (1), Michele Biff (2), Juliana Sicchieri (3), \\ Carla Barbosa Nonino (1), Fernanda Rodrigues de Oliveira Penaforte (4)
}

(1) Department of Internal Medicine, Faculty of Medicine of Ribeirão Preto, University of São Paulo, Ribeirão Preto, SP, Brazil

(2) Graduate Course of Nutrition, University of Extremo Sul Catarinense, Criciúma, SC, Brazil.

(3) Metabolic Unit, University Hospital, Faculty of Medicine of Ribeirão Preto, Ribeirão Preto, SP, Brazil.

(4) Graduate Course of Nutrition, Federal University of Triângulo Mineiro, Uberaba, Mg, Brazil.

\begin{abstract}
Introduction: Obesity is a disease characterized by excessive accumulation of body fat with health damaging effects. Objective: To assess the impact of two programs for the treatment of grade III obesity, hospitalization and ambulatory care, on weight loss and body composition. Methods: This was a retrospective study based on the analysis of the medical records of patients submitted to the above programs between 1990 and 2005, with evaluation of weight evolution, body circumferences (abdominal, hip and arm), fat mass (FM, kg) and fat-free mass (FFM, $\mathrm{kg}$ ). Results: A total of 50 medical records were evaluated, $54 \%$ of them concerning patients of the hospitalization program (HP). Both programs were efficient in promoting weight loss, however, it was greater for HP. HP led to reduction of all body circumferences and of FM but its cost was 80 times higher than the ambulatory program. Conclusion: On the basis of the data evaluated, despite its much higher cost, the HP yielded more effective results in terms of weight loss and change of body composition.
\end{abstract}

Key-words: obesity, weight loss program; hospitalization; outpatient clinic; body composition.

Este trabajo fue recibido el 7 de Septiembre de 2011 y aceptado para ser publicado el 1 de Marzo de 2012.

\section{INTRODUCTION}

Obesity is a disease characterized by excessive accumulation of body fat, usually as the consequence of a positive energy balance of such extent that it impairs the health of an individual $(1,2)$. It is considered to be an important public health problem, mainly due to the possible medical complications and the costs involved in its treatment (3). The treatment of obesity and of its consequences is estimated to consume 2 to $7 \%$ of the total health expenditures in developed countries (4). According to a survey of the Health Ministry, $43 \%$ of the adults of all Brazilian capital cities are overweight and $11 \%$ of these are obese (5).

There is strong evidence that weight loss reduces the risk factors for diabetes and cardiovascular disease, reduces arterial pressure and serum triglyceride levels and increases HDL-cholesterol in overweight or obese individuals. In addition, it usually causes some reduction of total serum cholesterol and LDL-cholesterol (6).

Programs for body weight reduction should focus on eating behavior and should develop effective interdisciplinary actions that would permit achieving effective 
results in the treatment of obesity (7). Public policies and programs must deal with the need for changes at the individual level, as well as the transformations of society and of the environment so that healthier options will become accessible and preferable (8). Educational actions regarding eating habits should be emphasized for this purpose (9).

The University Hospital of the Faculty of Medicine of Ribeirão Preto, University of São Paulo (FMRP-USP) provides programs for weight loss with different types of follow-up (ambulatory care and hospitalization). The programs last 8 weeks and mainly deal with grade III obese patients, their objectives being weight loss by means of energy restriction and changes of eating habits, as well as behavioral changes. For this purpose the programs count with a multidisciplinary team consisting of nutritionists nutrologists, psychologists and nurses, with constant patient monitoring during admission to the hospital (hospitalization program) or with weekly monitoring of patients receiving ambulatory care (ambulatory care program).

In view of the above considerations, the objective of the present study was to evaluate the impact of two programs for the treatment of grade III obesity (hospitalization and ambulatory care) on weight loss and body composition, and also their efficacy and cost-benefit. The results may contribute to the adoption of more effective strategies for the treatment of obesity in the hospital environment.

\section{SUBJECTS AND METHODS}

This was a retrospective study based on the analysis of the medical records of grade III obese patients submitted to programs for the treatment of obesity at the ambulatory level or by admission to the Nutrology Division of HCFMRP-USP. Both programs lasted 8 weeks and included diet modification and guidelines for behavioral changes aiming at achieving weight loss.

In the hospitalization program, the diet initially prescribed offers $1800 \mathrm{kcal} /$ day, andreductions in caloric content are made until reaching a minimum of 600 $\mathrm{kcal} /$ day. Reductions are made weekly, according to the clinical course of each patient. In addition, during the period of admission, patients received instructions on behavioral changes and nutritional orientation in order to encourage changes in eating habits. In the ambulatory program, dietary orientation was performed using food groups and their recommendations in portions, according to the Food Guide Pyramid (10), and also focused behavioral changes. The ambulatory consultations were weekly and performed by the same team responsible for the hospitalization program.
The sample consisted of all patients medical records of the hospitalization and the ambulatory program. For the hospitalization program, it were selected the patients who participated from 1990 (beginning of the program) to 2005; and those of the ambulatory program the selection was from 2002 to 2003 (period during which the program occurred), according to the inclusion criteria: both sexes, BMI between 40 and $60 \mathrm{~kg} . \mathrm{m}^{-2}$, age of 20 to 55 years and time of ambulatory follow-up, or time of hospitalization, of at least six weeks. The medical records of patients with infectious-contagious diseases, smokers, alcohol drinkers or patients engaged in any type of supervised physical activity were excluded. Thus, in a total of 200 medical records, 50 were selected by meeting all inclusion and exclusion criteria of the study.

Data about the history of disease, presence of comorbidities and previous treatments for weight loss were collected. The anthropometric data collected were weight, height and BMI. Weight and height were performed according to standardised techniques (11). Obesity was classified according to BMI (12). Some data were available only for the hospitalized group and therefore were evaluated only among the patients of that group. They referred to abdominal, hip and arm circumferences and to body composition (fat-free mass, FFM, fat mass, FM, and water) obtained by bioelectric impedance (BIA 101® Q-JL Systems, Clinton, MI, USA). All the circumferences were measured using an inextensible metric tape with $0.1 \mathrm{~cm}$ graduations, in accordance with the standardised techniques (13). All anthropometric and body composition measurements were accomplished by trained technician.

The costs of each program were also assessed based on the information obtained from the Costs Section of the Technical Consultancy Office of HCFMRP-USP. The informations about the period after the program, such as time of maintenance of weight loss and execution of bariatric surgery, were reported by patients in a structured questionnaire administered by telephone interview with patients whose addresses and/or telephone numbers had not been changed.

The study was approved by the Research Ethics Committee of HCFMRP-USP (protocol no 2082/2006) and all patients gave written informed consent to participate.

For statistical analysis, mean data were compared along time using a mixed-effects linear model. Comparison between groups was performed using ANOVA and the Student; t-test and the associations between variables were determined by linear regression models and by the Pearson correlation coefficient. Multiple 
linear regression models were used to determine the contribution of the variables to weight loss, and the nonparametric Friedman test and Dunn post-test were used for other comparison between variables. "p" values of less than 0.05 were considered to indicate statistical significance.

\section{RESULTS}

The medical records of 50 patients with grade III obesity were selected, with 27 of these patients participating in the weight loss program at the hospitalization level (hospitalized group) and 27 participating in the ambulatory program (ambulatory group). Most patients were females, $70.4 \%(n=19)$ in the hospitalized group and $69.6 \%(\mathrm{n}=16)$ in the ambulatory group.

Many of the individuals in both groups (48.1\% in the hospitalized group and $56.5 \%$ in the ambulatory group) had a history of the onset of obesity in childhood. Also, many individuals in the hospitalized group $(37.5 \%$ of the men and $47.3 \%$ of the women) and in the ambulatory group ( $71.4 \%$ of the men and $75.0 \%$ of the women) had used medication for weight loss previously. The most prevalent comorbidity associated with obesity was systemic arterial hypertension in both groups $(70.4 \%$ and $56.5 \%$, respectively), followed by type II diabetes mellitus (29.6\% and $13.0 \%)$ and dyslipidemia (22.2 and $13.0 \%$ ).

The initial weight $(145.4 \mathrm{~kg} \mathrm{x} 135.7 \mathrm{~kg}, \mathrm{p}<0.05)$ and BMI $\left(54.6 \mathrm{~kg} . \mathrm{m}^{-2} \times 50.0 \mathrm{~kg} \cdot \mathrm{m}^{-2}, \mathrm{p}<0.05\right)$ were significantly higher in the hospitalized group than in the ambulatory group. When the patients were considered separately according to sex, this difference was maintained only for females. The maximum and minimum weights detected were $200.5 \mathrm{~kg}$ and $103.3 \mathrm{~kg}$ for the hospitalized group, respectively, and $176.0 \mathrm{~kg}$ and 102.0 $\mathrm{kg}$ for the ambulatory group. The women of the hospitalized group were older than those of the ambulatory group $(\mathrm{p}<0.01)$, and the initial weight was greater in men than in women in both groups (table 1).

The weekly weight evolution of patients of both groups from the beginning to the end of treatment is presented in table 2 . There was a significant weight reduction $(\mathrm{p}=0.01)$ in both sexes as early as by the 1 st week (T1) in the hospitalized group and by the 2 nd week (T2) in the ambulatory group, being maintained until the end of the program in both groups.

When weight loss was compared between sexes within each group, it was observed that men lost significantly more weight than women in the ambulatory group $(5.0 \%$ and $3.1 \%$, respectively, $\mathrm{p}=0.02)$. In contrast, in the hospitalized group there was no significant difference between sexes in weight loss, which was on average $9.5+2.32 \%$ for women and $10.82+1.76 \%$ for men Comparison of weight loss between groups revealed a significantly greater loss in the hospitalized group in both sexes ( $\mathrm{p}=0.01)$, with a weekly weight loss of 2.1 $+0.7 \mathrm{~kg} /$ week for the hospitalized group and of $0.7+$ $0.7 \mathrm{~kg} /$ week for the ambulatory group.

For the hospitalized patients it was possible to evaluate data regarding body circumferences and body composition during the program. There was a significant reduction at the final time point compared to the initial one for all of these measurements in both sexes. Regarding the body proportions of FFM, FM and body water, there was a decrease in percent FM and an increase in FFM and water in both sexes (table 3).

According to the information of the costs center of HCFMRP-USP, the estimated total cost per patient

\section{TABLE 1}

Initial characteristics of the patients in the hospitalized and ambulatory care groups (mean+ SD).

\begin{tabular}{|lccc|}
\hline \multicolumn{1}{|c}{ Hospitalized group } & General & Male & Female \\
\hline Age $($ years $)$ & $39.2+9.4$ & $34.2+13.1$ & $41.3+6.7 *$ \\
Weight $(\mathrm{kg})$ & $145.5+25.0^{* *}$ & $163.3+24.9$ & $138.0+21.4$ \\
BMI $\left(\mathrm{kg} / \mathrm{m}^{-2}\right)$ & $54.6+6.7$ & $54.9+6.2$ & $54.5+7.0 * *$ \\
Ambulatory care group & & & \\
Age (years) & $35.4+11.7$ & $32.86+13.5$ & $36.6+11.1 *$ \\
Weight $(\mathrm{kg})$ & $135.7+21.6 * *$ & $158.5+13.2$ & $125.7+16.3$ \\
BMI $\left(\mathrm{kg} / \mathrm{m}^{-2}\right)$ & $50.1+5.0$ & $51.5+6.04$ & $49.4+4.4 * *$ \\
\hline$* \mathrm{p}=0.01$ (hospitalized group $\mathrm{X}$ ambulatory care group); $* * \mathrm{p}<0.05$ (hospitalized group X ambulatory care group). \\
\hline
\end{tabular}


was approximately $\mathrm{R} \$ 14,899(\mathrm{R} \$ 266.0 \pm 53.8$ /patient/ day) for the hospitalization program and $\mathrm{R} \$ 184.20(\mathrm{R} \$$ $23.0 \pm 6.2 /$ patient/day) for the ambulatory program, with the total cost of the hospitalization program being approximately 81 times higher than that of the ambulatory program. However, it should be considered that the hospitalized patient remained in the hospital for 8 weeks while the ambulatory patients came to the hospital only once a week for a visit over a period of 8 weeks.

The following results were obtained when the 15 patients of the hospitalized group and the 18 patients of the ambulatory group were contacted at various times after treatment: the time of maintenance of weight loss among most of the patients in the hospitalized group $(66.7 \%)$ was more than 10 months, whereas many of the ambulatory patients $(44.5 \%)$ maintained it for less than 9 months. At the time of contact, most of the patients in the hospitalized and ambulatory groups $(60.0 \%$ and $55.5 \%$, respectively) reported that they had already been submitted to bariatric surgery.

\section{TABLE 2}

Weight evolution (kg) of the patients in the ambulatory care group and in the hospitalized group during the 8 weeks of the program (mean+SD).

\begin{tabular}{|ccccc|}
\hline & \multicolumn{2}{c}{ Ambulatory care group } & \multicolumn{2}{c|}{ Hospitalized group } \\
Time & Female & Male & Female & Male \\
\hline 0 & $125.7+16.3$ & $158.5+13.2$ & $138.0+21.4$ & $163.3+24.9$ \\
1 & $124.8+16.7$ & $157.3+14$ & $129.4+17.4 *$ & $158.0+24.6 *$ \\
2 & $124.1+17 *$ & $155.4+13.7 *$ & $132.0+20.6 *$ & $156.3+26.0 *$ \\
3 & $123.6+17 *$ & $154+14.2 *$ & $132.3+20.4 *$ & $154.1+25.6 *$ \\
4 & $123.4+16.7 *$ & $151.9+18 *$ & $129.3+20.4 *$ & $152.4+24.6 *$ \\
5 & $122.6+17 *$ & $152.6+14.5 *$ & $123.3+16.9 *$ & $150.2+24.0 *$ \\
6 & $119.9+17.6 *$ & $151.8+15.2 *$ & $121.3+16.6 *$ & $146.9+23.3 *$ \\
7 & $123.6+17.2 *$ & $151+15.7 *$ & $123.0+18.9 *$ & $145.5+23.1 *$ \\
8 & & & $128.9+21.4 *$ & \\
\hline$* \mathrm{p}=0.01$ (difference compared to T0) & & & \\
\hline
\end{tabular}

\section{TABLE 3}

Anthropometric and body composition evolution of the hospitalized group, both sexes (mean+ SD).

\begin{tabular}{|c|c|c|c|c|}
\hline & \multicolumn{2}{|c|}{ Male } & \multicolumn{2}{|c|}{ Female } \\
\hline & Initial & Final & Initial & Final \\
\hline Weight (kg) & $163.3+24.9$ & $145.5+23.1^{*}$ & $138.0+21.4$ & $128.9+21.4 *$ \\
\hline $\mathrm{AC}(\mathrm{cm})$ & $46.1+3.3$ & $44.3+2.6 *$ & $45+5.6$ & $42.2+4.7 *$ \\
\hline $\mathrm{AbC}(\mathrm{cm})$ & $157.7+9.5$ & $151.6+5.0 *$ & $136.5+14.2$ & $122.8+17.9 *$ \\
\hline $\mathrm{HC}(\mathrm{cm})$ & $158.3+17.5$ & $150.8+18.8 *$ & $150.2+12.4$ & $141.8+10.8 *$ \\
\hline FFM $(\%)$ & $58.3+5.7$ & $59.5+6.3^{*}$ & $48.8+6.7$ & $51.1+5.3^{*}$ \\
\hline $\mathrm{FM}(\%)$ & $41.7+5.7$ & $40.5+6.3^{*}$ & $51.2+6.7$ & $48.9+5.3^{*}$ \\
\hline Water (\%) & $42.7+4.2$ & $43.5+4.5^{*}$ & $35.7+4.8$ & $37.7+3.7 *$ \\
\hline
\end{tabular}




\section{DISCUSSION}

At the end of both programs, the patients obtained a significant weight loss and a good part of the hospitalized patients maintained this loss for a period of more than 10 months, while the ambulatory patients maintained it for less than 9 months. The weight loss obtained is considered to be important from a clinical viewpoint, having a positive impact on the health of these patients, but the costs involved in the programs as well as in alternative treatments should be considered in the overall evaluation of treatment.

The most prevalent comorbidity in both the hospitalized and ambulatory groups was systemic arterial hypertension, followed by type 2 diabetes mellitus and dyslipidemia. According to Bray (14), it has been well established that obese individuals have an increased frequency of systemic arterial hypertension, diabetes mellitus and coronary artery disease.

The Institute of Medicine of the National Academy of Sciences (1995) has proposed that successful weight loss can be defined as a reduction of $5 \%$ or more of the initial weight and maintenance of this loss for at least one year. A modest weight reduction $(5-10 \%$ of the initial weight) leads to an improvement of cardiovascular risk factors among obese individuals (15). The two groups studied here showed a significant weight reduction at the end of treatment, with hospitalized patients showing a more satisfactory result, achieving a weight loss of approximately $10 \%$ of the initial weight. Similar results were reported by Tseng et al. (16), who detected a weight loss of approximately $8 \%$ at the end of a 12 week program directed at obese patients in the hospital environment.

In contrast, in the present ambulatory group the weight loss was significantly lower compared to the hospitalized group, being about 5\% for men and 3\% for women. Porto et al. (3), in a study of grade III obese patients under ambulatory treatment for weight loss with a multidisciplinary team for a period of approximately $20+17$ months, observed that $26.6 \%$ of the individuals showed a weight loss of $5 \%$ or more of the initial weight and $12.4 \%$ showed a reduction of $10 \%$ or more. In general, weight reduction based on a diet is unsatisfactory for obese patients followed up on an ambulatory basis (17), but is extremely effective for hospitalized patients (18). The lower weight loss of the ambulatory group may also be due to an insufficient follow-up period. Since the patients are followed up on a weekly basis, a longer time of intervention may be necessary for them to achieve a greater and more satisfactory weight loss. There are no data indicating an optimal frequency for ambulatory programs. Nevertheless it has been suggested that treatment should last at least 4 months with visits once or twice a week (19). Offering more than 10 weeks of treatment may bring benefits, but also involves increased costs. However, considering the extremely high costs of obesity for the Brazilian health care system, the investment of resources of this level in ambulatory programs could be advantageous (20).

One of the factors that might have contributed to the greater weight loss in the hospitalized group was the fact that these individuals were under constant supervision of the team. In addition, at each meal, the patients received their diets prepared according to the prescription of the treatment team. Thus, they ingested what was offered, without having access to other types of foods, a fact that definitely facilitates adherence to the dietary guidelines. It is known that at home it is more difficult to follow the guidelines since there are other family members and greater availability of food types and quantities, which represent a challenge for the ambulatory patient, when he has to choose certain foods and refuse others. In addition, frequent contact with professionals during diet therapy helps promote weight loss and maintenance of reduced weight. The results of the inpatient program showed greater efficacy in this type of assistance, offered mainly by improved monitoring food intake and strengthening the bond of health staff and patients, reinforcing the motivation to proceed with the diet. Keeping adherence to very restrictive diets for prolonged periods is one of the factors of therapeutic failure when the patients are attended ambulatory $(6,26)$.

Weight loss is expected to be the result of reduced body fat with a minimal loss of lean mass, reducing the risks of malnutrition and of clinical complications. All segments evaluated here in the hospitalized group (FFM, FM and water) showed a significant weight reduction at the end of the program. Men lost a greater percentage of arm and hip circumference, FFM and water and women lost a greater percentage of abdominal circumference and FM. The association of the percent loss of these measurements with total weight loss showed that the reduction of fat mass was the one that most contributed to percent weight loss although there was an unavoidable loss of FFM. At the end of the program there was an increase in percent FFM and a decrease in body FM, reflecting a greater FM loss and a relative maintenance of FFM. The variables gender, age and initial weight did not influence total weight loss, supporting the results of Compe et al (21) who did not find an influence of gender, age or physical activity on weight loss.

Among hospitalized men, percent FFM loss was higher but it should be pointed out that water loss was also higher, suggesting that loss of muscle tissue was 
not so different between genders. A similar result was detected in a weight loss program involving 3 weeks of hospitalization and one year of follow-up, in which men showed a greater FFM loss than women (22).

Weight loss programs involving behavioral changes have shown a positive association between weight loss and duration of treatment, hours of contact with a professional, experience of the professional, use of a rigorous diet, practice of physical activity, and involvement of the patient's family. Obesity should not be treated as an "acute care model", but rather should be seen as a chronic disease requiring constant clinical care (23).

An average total cost of $\mathrm{R} \$ 14,899.00$ (US $\$ 9,254$ ) per patient is estimated at the end of an 8 week program of hospitalization. This total is much higher than that estimated for an ambulatory program of weight loss, including an intensive phase of 8 consultations per week, plus monthly sessions for 10 months to complete one year of maintenance, corresponding to an average cost of about R $\$ 415.00$ (US\$ 258.00). It should be pointed out that at the outpatient clinic the clinical-nutritional evaluation is not the same as in the hospital, where anthropometric, biochemical and body composition tests are performed, nor is the same daily drug and dietary monitoring available. Martin et al. (24) estimated that the cost of a program for weight loss, including the phase of evaluation, weekly group sessions for 6 months and one year of maintenance would be approximately U\$3,000.

When the programs were initiated, the focus was on weight reduction and treatment of other weight problems. Until this survey, data on economic investments were unknown. This study presented a contribution to the better cost-benefit of programs, as well as possible modifications that resulted in better utilization of hospitalization period. Family involvement in treatment, development of recipes for implementation at home, intensified psychological care, and early complementary therapies for weight reduction, such as physical therapy, were changes incorporated into the program since its beginning.

Surgical treatment of obesity must be included in this discussion since most of the patients interviewed by phone $(58 \%)$ reported that they had been submitted to bariatric surgery (60\% of the hospitalized individuals and $56 \%$ of the ambulatory individuals). At the same hospital, the mean estimated cost per patient, including one week for initial evaluation and the surgical procedure, is about US\$ 4534.00. This amount is still lower than the cost of hospitalization for 8 weeks, but it should be remembered that bariatric surgery involves a much greater volume of expenses due to the need for long-term follow-up and the frequent hospitalizations for the treatment and control of the complications associated with the surgical procedure. Analysis of the cost-benefit of the treatment of obesity shows that the benefit is about 3 times greater than the cost and does not depend on the quantity of weight loss within a short period of time, but rather on the maintenance of such loss for a long time (25).

Telephone contact was made with $55 \%$ of the patients in the hospitalized group and $78 \%$ of the patients in the ambulatory group. The time of maintenance of weight loss after the end of the programs was longer among the hospitalized patients than the ambulatory ones. Evidence suggests that more than $80 \%$ of persons who lose weight will gradually regain it, although patients who continue treatment in programs of weight loss maintenance have a better chance of maintaining this loss. The maintenance phase consists of continued contact with the health professional for continued education, support and monitoring (diet, physical activity and behavioral therapy) (6). The longer time of maintenance of weight loss in the hospitalized group may have been due to the fact that these individuals remained under the constant supervision and counseling of the team throughout the program. In addition, for the hospitalized patients the foods of each meal were already selected regarding type and quantity, permitting a greater fixation of the guidelines by visualization of what would be appropriate for the patients to consume, considering that these diets were adapted for continued use at home after hospital discharge.

We conclude that the hospitalization program, despite its higher cost, yielded better results in terms of weight evolution, with maintenance of weight loss for a longer period of time than observed in the subjects of the ambulatory program. The hospitalization program permitted a weight loss considered to be satisfactory from the clinical viewpoint in both sexes with a relative improvement of body composition leading to a greater loss of fat mass and a certain maintenance of FFM and water. However, the success of a nutritional treatment of obesity should not be evaluated only in terms of the weight loss achieved in the short term, but also by considering the establishment of realistic goals of changes in life style that will lead to a slow, but definitive, weight loss. To this end, it is of fundamental importance to institute a phase of maintenance, with definitive changes in eating habits, thus contributing to the maintenance of the weight loss achieved by these individuals.

\section{RESUMEN}

Introducción: La obesidad es una enfermedad caracterizada por la acumulación excesiva de grasa corporal, 
con efectos nocivos para la salud. Objetivo: Evaluar el impacto de dos programas para el tratamiento de la obesidad grado III: hospitalización y ambulatorio, en la pérdida de peso y composición corporal. Método: Se realizó un estudio retrospectivo basado en el análisis de las historias clínicas de los pacientes sometidos a los dos programas, entre 1990 y 2005, con la evaluación de la evolución del peso, circunferencias corporales (cadera, abdominal, y del brazo), la masa grasa ( $\mathrm{MG}, \mathrm{kg}$ ) y masa libre de grasa (MLG, kg). Resultados: Un total de 50 historias clínicas fueron evaluadas, siendo la mayoría (54\%), de los pacientes del programa de hospitalización (PH). Los dos programas fueron eficaces en la promoción de la pérdida de peso, pero esta pérdida fue mayor para el PH; que llevó a una reducción de todas las medidas de las circunferencias corporales y de la MG. Sin embargo, su costo fue 80 veces mayor que el del programa de ambulatorio. Conclusión: Sobre la base de los datos evaluados, a pesar de su costo mucho más alto, el HP dió resultados más eficaces en términos de pérdida de peso y en el cambio de la composición corporal. Palabras clave: obesidad, programa de pérdida de peso, hospitalización, consultas externas, composición corporal.

Dirigir la correspondencia a:

Profesor

Paula Garcia Chiarello

Av. Bandeirantes, 3900

Bairro Monte Alegre

Ribeirão Preto - SP, Brazil; 14049-190

Fax: (16)3602-3096

E-mail: paulagc@fmrp.usp.br

\section{BIBLIOGRAFÍA}

1. World Health Organization. Obesity: preventing and managing the global epidemic. Report of a WHO consultation, 2000.

2. World Health Organization Obesity and overweight Disponível em. Sttp.//www who int/ mediacentre/factsheets $\square \mathrm{fs} 311 \square$ en $\square$ print.htmp. acesso em 07/março/2009.

3. Porto MCV et al. Perfil do obeso classe III do ambulatório de obesidade de um hospital universitário de Salvador, Bahia. Arq Bras Endocrinol Metab 2002; 46 (6): 668- 73.

4. World Health Organization. Preventing and managing the global epidemic. Report of a WHO consultation on obesity. Geneve, 1998.

5. MINISTÉRIO DASAÚDE Relatório vigitel, 2006 Disponível em. http./portal saude gov hr/portal arquivos/pdf/relatorio_vigitel_2006_março_2007. pdip

6. American Society For Clinical Nutrition. Clinical guidelines on the identification, evaluation and treatment of overweight and obesity in adults: executive summary. Expert panel on the identification, evaluation and treatment of overweight in adults. Am J Clin Nutr 1998; 68: 899-917.

7. Bernardi F, Cicherelo C, Vitolo MR. Comportamento de restrição alimentar e obesidade. Rev Nutr 2005; 18 (1): 85-93.

8. World Health Organization. Relatório conjunto dos especialistas da OMS/FAO em dieta, nutrição e prevenção de doenças crônicas. 13a reunião interamericana, a nível ministerial, sobre saúde e agricultura. Washington DC, 2003.

9. Monteiro C.A. Velhos e novos males da saúde no Brasil: São Paulo, 2000, pp 247-55.

10. Philippi ST et al. Pirâmide alimentar adaptada: guia para a escolha dos alimentos. Rev Nutr 1999; 12 (1): $65-80$.

11. BRASIL (2004) Sistema de Vigilância alimentar e nutricional - SISVAN: orientações básicas para a coleta, processamento, análise de dados e informação em serviços de saúde. Brasília-DF: Ministério da Saúde, Brasil.

12. World Health Organization (1998) Obesity: Preventing and Managing the Global Epidemic. Report of a WHO Consultation Technical Report Series no. 894. Geneva: World Health Organization.

13. Callway, C.W., Chumlea, W.C., Bouchard, C., Himes, J.H., Lohman, T.G., Martin, A.D., Micthell, C.D., Mueller, W.H., Roche, A.F. \& Seefeldt, V.D. (1988) Circumferences. In Anthropometric Standardization Reference Manual. eds T.G. Lohman, A.F. Roche \& R. Martorell, pp. 39-54. Champaign, IL: Human Kinetics.

14. Bray GA. Pathophysiology of obesity. Am J Clin Nutr 1992; 55: 488-94.

15. National Institutes Of Health. Clinical guidelines on the identification, evaluation and treatment of overweight and obesity in adults. Evidence report. Obes Res 1998 ; 6:S51-S209.

16. Tseng MC et al. Psychobehavioral response and weight loss prediction in a hospital-based weight reduction program. J Formos Med Assoc 2002, 101 (10): 705-11.

17. Glenny AM et al. The treatment and prevention of obesity: a systematic review of literature. Int J Obes 1997; 21: 715-37.

18. Bortz WM. A 500 pound weight loss. Am J Med 1969; 47: 325-331.

19. Weinsier RLet al. Recommended therapeutic guide- 
lines for professional weight control programs. Am J Clin Nutr 1984; 40: 865-72.

20. Kumanyika SK et al. Outpatient weight management in African-Americans: the healthy eating and lifestyle program (HELP) study. Preventive Med 2005; 41: 488-502.

21. Compe A, Papoz L, Avignon A. Outcome of patients consulting in an outpatient nutrition clinic for excessive body weight. Diabetes Metab 2003; 29: 519-24.

22. Maffiuletti NA et al. Changes in body composition, physical performance and cardiovascular risk factors after a 3-week integrated body weight reduction program and after 1-y follow-up in severely obese men and women. Eur J Clin Nutr 2005; 59 (5): 685-94.

23. Wing RR. Behavioral treatment of severe obesity. Am J Clin Nutr 1992; 55: S545-S51.

24. Martin LF et al. Comparison of the costs associated with medical and surgical treatment of obesity. Surgery 1995; 118: 599-607.

25. Yates J, Murphy CA. Cost benefit analysis of weight management strategies. Asia Pac Clin Nutr 2006; 15: 74-9.

26. Assis MAA, Nahas MV. Aspectos motivacionais em programas de mudança de comportamento alimentar. Rev Nutr 1999; 12 (1): 33-41. 